\title{
I 32 Coronary vessel wall evaluation by MRI in the Multi-Ethnic Study of Atherosclerosis (MESA): physiologic determinants of image quality
}

\author{
Ashkan A Malayeri*1, Robson Macedo1, Debiao Li², Shaoguang Chen', \\ Hossein Bahrami ${ }^{3}$, Shenghan Lai ${ }^{3}$, João AC Lima ${ }^{3}$ and David A Bluemke ${ }^{1}$
}

Address: ${ }^{1}$ Johns Hopkins Hospital, Department of Radiology and Radiological Sciences, Baltimore, USA, ${ }^{2}$ Northwestern University Medical School, Department of Radiology, Chicago, IL, USA and 3Johns Hopkins Hospital, Cardiology Division, Deptartment of Internal Medicine, Baltimore, USA

* Corresponding author

from I I th Annual SCMR Scientific Sessions

Los Angeles, CA, USA. I-3 February 2008

Published: 22 October 2008

Journal of Cardiovascular Magnetic Resonance 2008, I0(SuppI I):A33 doi:I0.I I86/I532-429X-10-SI-A33

This abstract is available from: http://jcmr-online.com/content/I0/SI/A33

(C) 2008 Malayeri et al; licensee BioMed Central Ltd.

\section{Introduction}

Coronary artery wall magnetic resonance imaging (MRI) has been developed to assess coronary lumen diameter and wall thickness.

\section{Purpose}

The purpose of this study was to evaluate physiologic parameters that affect measures of coronary wall thickness using black blood MRI pulse sequences.

\section{Methods}

87 participants (M: 38, F: 49) of the Multi-Ethnic Study of Atherosclerosis (MESA) were enrolled in the coronary artery wall MRI study. Cine four chamber imaging was used to determine the coronary artery rest period. Free breathing whole heart magnetic resonance angiography (MRA) with motion adaptor navigator was performed to localize the coronary arteries. Cross-sectional free breathing black-blood images were acquired using ECG-gated, turbo spin echo (TSE) sequence. Six images were acquired from left anterior descending artery (LAD) and right coronary artery (RCA) and one image was planned on the left main (LM) artery (Figure 1). Imaging parameters were TR $=2 \mathrm{R}-\mathrm{R}$ intervals, $\mathrm{TE}=33 \mathrm{~ms}$, echo train length $=13$, bandwidth $=305 \mathrm{~Hz} /$ pixel, matrix $=416 \times 416$, field of view $=$ $420 \times 420 \mathrm{~mm}$ and slice thickness $=4-5 \mathrm{~mm}$.

\section{Results}

Imaging was completed in 215/234 (92\%) coronary segments; 9 participants had incomplete scans. Mean age was $62.6 \pm 8.4$ years $(45-81$ years). Mean body mass index (BMI) was $29.2 \pm 5.9 \mathrm{~kg} / \mathrm{m}^{2}$. A higher proportion of images with quality of "good" was seen in the RCA (40.5\%) compared to the LM and LAD $(31.9 \%$ and $26.4 \%$, respectively). There was very good agreement between observers in the image quality scores (kappa = $0.79, \mathrm{P}<0.001)$. Lower heart rate, male gender and longer coronary rest period were associated with higher image quality score $(\mathrm{p}<0.05)$. SNR was higher in participants with Agatston calcium score of more than 10 in the RCA and LM arteries ( 48.5 vs. $69.7, \mathrm{p}=0.001 \& 53.4$ vs. 61.6, $\mathrm{p}=0.032$ ).

\section{Conclusion}

Improved depiction of the coronary artery wall with MRI is related to coronary rest period and atherosclerotic plaque burden as measured by calcium score and inversely related to heart rate. Since longer coronary artery rest periods are associated with improved image quality both for angiography with MRI and coronary artery wall imaging, heart rate lowering methods in association with these techniques appear to be a logical application. 

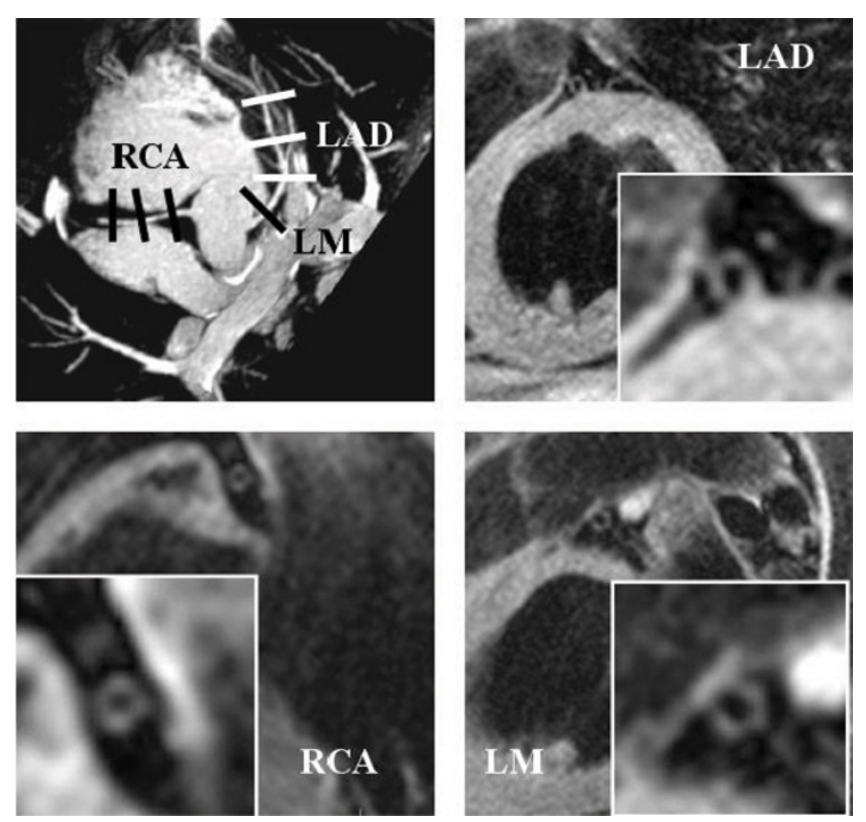

\section{Figure I}

Purpose of this study was to evaluate the role of physiologic parameters in coronary vessel wall imaging. Improved depiction of the coronary artery wall is related to coronary rest period, atherosclerotic plaque burden and inversely related to heart rate.

Publish with Bio Med Central and every scientist can read your work free of charge

"BioMed Central will be the most significant development for disseminating the results of biomedical research in our lifetime. "

Sir Paul Nurse, Cancer Research UK

Your research papers will be:

- available free of charge to the entire biomedical community

- peer reviewed and published immediately upon acceptance

- cited in PubMed and archived on PubMed Central

- yours - you keep the copyright 